\title{
Structural basis of human ghrelin receptor signaling by ghrelin and the synthetic agonist ibutamoren
}

Cheng Zhang ( $\nabla$ chengzh@pitt.edu )

University of Pittsburgh https://orcid.org/0000-0001-9042-4007

Heng Liu

University of Pittsburgh

\section{Dapeng Sun}

University of Pittsburgh https://orcid.org/0000-0003-0220-8844

\section{Alexander Myasnikov}

St. Jude Children's Research Hospital

Marjorie Damian

CNRS, Université de Montpellier, ENSCM

Jean-Louis Baneres

IBMM https://orcid.org/0000-0001-7078-1285

Ji Sun

St. Jude Children's Research Hospital https://orcid.org/0000-0002-9302-3177

\section{Article}

Keywords: ghrelin, hunger hormone, cell signaling

Posted Date: July 12th, 2021

DOl: https://doi.org/10.21203/rs.3.rs-646701/v1

License: (c) (i) This work is licensed under a Creative Commons Attribution 4.0 International License.

Read Full License

Version of Record: A version of this preprint was published at Nature Communications on November 4th, 2021. See the published version at https://doi.org/10.1038/s41467-021-26735-5. 
Structural basis of human ghrelin receptor signaling by ghrelin and the synthetic agonist ibutamoren

Heng Liu ${ }^{1}$, Dapeng Sun ${ }^{1}$, Alexander Myasnikov ${ }^{2}$, Marjorie Damian ${ }^{3}$, Jean-Louis Baneres ${ }^{3}$, Ji Sun $^{2 *}$, Cheng Zhang ${ }^{1^{*}}$

${ }^{1}$ Department of Pharmacology and Chemical Biology, School of Medicine, University of Pittsburgh, Pittsburgh, PA15261, USA

${ }^{2}$ Department of Structural Biology, St. Jude Children's Research Hospital, Memphis, Tennessee, TN38120, USA

${ }^{3}$ Institut des Biomolécules Max Mousseron, CNRS, Université de Montpellier, ENSCM, Montpellier, France

${ }^{*}$ Correspondence: Dr. Ji Sun, Ji.Sun@stjude.org or Dr. Cheng Zhang, chengzh@pitt.edu. 


\begin{abstract}
The 'hunger hormone' ghrelin activates the ghrelin receptor GHSR to stimulate food intake and growth hormone secretion and regulate reward signaling. Acylation of ghrelin at Ser3 is required for its agonistic action on GHSR. Synthetic agonists of GHSR are under clinical evaluation for disorders related to appetite and growth hormone dysregulation. Here, we report high-resolution cryo-EM structures of the GHSR-G $\mathrm{G}_{i}$ signaling complex with ghrelin and the non-peptide agonist ibutamoren as an investigational new drug. Our structures together with mutagenesis data reveal the molecular basis for the binding of ghrelin and ibutamoren. Structural comparison suggests a salt bridge and an aromatic cluster near the agonist-binding pocket as important structural motifs in receptor activation. Notable variations of the $\mathrm{G}_{\mathrm{i}}$ binding mode are observed in our cryo-EM analysis, indicating highly dynamic nature of $\mathrm{G}_{\mathrm{i}}$-coupling to GHSR. Our results provide a framework for understanding GHSR signaling and developing new GHSR agonist drugs.
\end{abstract}




\section{Introduction}

The human ghrelin system is a critical component of the gut-brain axis to regulate energy homeostasis and reward signaling ${ }^{1-3}$. Ghrelin is a 28 -amino acid orexigenic peptide hormone generated in the gut commonly regarded as the 'hunger hormone' or 'survival hormone' ${ }^{1-4}$. It mainly signals through the growth hormone secretagogue receptor (GHSR, or ghrelin receptor), a class A G protein-coupled receptor (GPCR). Ghrelin signaling through GHSR to stimulate growth hormone secretion and food intake under nutritional or physiological challenges ${ }^{1,2}$. In addition, GHSR plays critical roles in the modulation of stress and anxiety ${ }^{5,6}$ and the regulation of dopamine signaling and thus reward pathways in the CNS 7,8 . Therefore, GHSR is a highly pursued drug target $^{9}$. A GHSR inverse agonist named PF-5190457 is under clinical investigation to treat alcohol use disorder ${ }^{10,11}$. On the other hand, pharmacological stimulation of GHSR by agonists represents an emerging and exciting avenue to address disorders related to appetite, gastric emptying and growth hormone dysregulation. Relamorelin and anamorelin are two synthetic peptide agonists of GHSR that are in different stages of clinical trials to treat diabetic gastroparesis and cancer-related anorexia-cachexia ${ }^{12-16}$. Ibutamoren, also known as MK-0677 or LUM-201, is a synthetic smallmolecule GHSR agonist used as a growth hormone secretagogue in many disease settings ${ }^{9,17-20}$.

The ghrelin-GHSR signaling system exhibits several unique properties compared to other GPCR signaling systems. Acylation of ghrelin, usually octanoylation at position-3 serine, is required for its action on GHSR ${ }^{3}$. Such a modification is achieved by the ghrelin O-acyl-transferase (GOAT) in vivo ${ }^{21-23}$. Acylated ghrelin can activate GHSR to signal through multiple protein partners, including the $G_{q / 11}$ and $G_{i / 0}$ families of $G$ proteins and $\beta$-arrestins ${ }^{24}$. Several studies showed that different GHSR signaling pathways regulate distinct physiological functions ${ }^{25-27}$. The GHSR and $\mathrm{G}_{\mathrm{i}}$ signaling pathway has been linked to attenuated glucose-induced insulin release by ghrelin ${ }^{25}$, while the appetite stimulation is mainly mediated by $\mathrm{G}_{\mathrm{q} / 11}$ signaling ${ }^{26}$. GHSR also exhibits a remarkably high constitutive activity, which is important for physiological growth hormone regulation ${ }^{28}$. Mutations of the GHSR gene that result in loss of GHSR constitutive activity have been associated with the familial short stature syndrome ${ }^{29}$. In addition, the constitutive activity of GHSR is negatively regulated by several endogenous mechanisms. Liver expressed antimicrobial peptide 2 (LEAP2) has been characterized as a GHSR inverse agonist or antagonist ${ }^{30}$. Melanocortin receptor accessory protein 2 (MRAP2), a single-pass transmembrane protein, can directly associate with GHSR to modulate its activity ${ }^{3,31}$.

Due to the physiological and pathological significance of the ghrelin-GHSR system, intensive research effort has been devoted to the molecular understanding of ghrelin action and GHSR signaling. Biophysical studies and structural modeling were performed to investigate ghrelin recognition by GHSR ${ }^{32,33}$. Recently, a crystal structure of highly engineered GHSR at an inactive conformation bound to an antagonist, Compound 12 (C12), has been reported to probe a possible ghrelin recognition mechanism ${ }^{34}$. Yet, the molecular mechanism underlying GHSR signaling by diverse peptide and non-peptide agonists still remains elusive. Here, we report two cryo-electron 
microscopy (cryo-EM) structures of human GHSR in complex with $\mathrm{G}_{i}$ and two agonists, the endogenous ligand ghrelin and the non-peptide synthetic agonist ibutamoren. Structural analysis together with mutagenesis data revealed mechanisms underlying agonism of different types of GHSR agonists and GHSR-G $\mathrm{G}_{\mathrm{i}}$ coupling.

\section{Results and Discussion}

\section{Structure determination of two GHSR-G $\mathrm{G}_{\mathbf{i}}$ complexes and overall structures}

We used wild type human GHSR and human $\mathrm{G}_{\alpha \mathrm{\alpha i}}, \mathrm{G}_{\beta 1}$ and $\mathrm{G}_{\gamma 2}$ to assemble the complexes with two agonists. No modification was introduced to the $G_{i}$ heterotrimer except for the amino-terminal 6xHis tag in $\mathrm{G}_{\beta 1}$. We used apyrase to hydrolyze GDP in order to form stable nucleotide-free complexes. We also added an antibody fragment, scFv16, to further stabilize the $\mathrm{G}_{\mathrm{i}}$ heterotrimer

35. The structures of the GHSR-G $\mathrm{G}_{\mathrm{i}} \mathrm{ScFv} 16$ complexes with ghrelin and ibutamoren were both determined to an overall resolution of $2.7-\AA \AA$ (Fig. 1a and b, Extended Data Fig. S1). The cryoEM maps allowed modeling of most regions of GHSR and $\mathrm{G}_{\mathrm{i}}$ heterotrimer, ghrelin residues Gly1Val12 (residues in ghrelin are referred to by three-letter names, and residues in GHSR and other GPCRs are referred to by one-letter names hereafter) together with the octanoyl group, and the entire ibutamoren molecule (Fig. 1a and b, Extended Data Fig. S1).

We also observed cryo-EM densities likely corresponding to cholesterol molecules bound to GHSR in both structures (Extended Data Fig. S2a). Further experiments showed that cholesterol could positively regulate the activity of GHSR in reconstituted lipid nanodiscs (Extended Data Fig. S2b), suggesting a potentially significant physiological role of cholesterol in ghrelin signaling.

\section{Ghrelin and ibutamoren recognition}

In our structure, the N-terminal part of ghrelin adopts an extended conformation and inserts into a deep pocket of GHSR (Fig. 2a); such a binding mode is different from the predicted ghrelin binding mode based on the previous crystal structure ${ }^{34}$. It was suggested that the salt bridge between E124 $4^{3.33}$ and R283 ${ }^{6.55}$ (superscripts represent Ballesteros-Weinstein numbering ${ }^{36}$ ) of GHSR divides the ghrelin-binding pocket into two cavities, cavity I and $\mathrm{II}^{34}$. In our structures, we also observed this salt bridge. All the peptide moiety of ghrelin occupies the large cavity I while the octanoyl moiety attached to Ser3 of ghrelin extends into the small cavity II (Fig. 2a). It has been proposed that a crevasse region separating TM6 and TM7 in the inactive GHSR structure served as the recognition site of octanoyl moiety of ghrelin ${ }^{34}$. However, our structure didn't support this hypothesis but instead showed that TM7 shifts towards TM6 compared to that in the inactive GHSR, closing the previously observed crevasse in the inactive structure (see discussion below).

Ghrelin engages in extensive polar and hydrophobic interactions with GHSR in the cavity I. From the bottom region to the extracellular side, the side chains of ghrelin residues Glyl and Glu8 form salt bridges with the side chains of E124 $4^{3.33}$ and R107 ${ }^{\text {ECL1 }}$ of GHSR, respectively; the side chains of Ser2 and Arg11 and the main chain carbonyl of Phe4 of ghrelin are hydrogen- 
bonded by the main chain carbonyl groups of F290 ${ }^{\mathrm{ECL} 2}$ and S308 7.38 and the side chain of Y106 of GHSR, respectively (Fig. 2a). In addition to these polar interactions, in the middle region of the cavity II, Phe4 of ghrelin packs against GHSR residues L103 ${ }^{2.64}$, L306 ${ }^{7.36}$ and F309 ${ }^{7.39}$ to form hydrophobic interactions (Fig. 2a). Leu5 of ghrelin also forms hydrophobic interactions with GHSR residues F286 6.58 and F2906.62 (Fig. 2a).

The octanoyl moiety of ghrelin mainly occupies the cavity II with an extended conformation pointing towards the cleft between TM4 and TM5 (Fig. 2b). We observed a strong density corresponding to the proximal half of the octanoyl moiety, while the density for the distal half was not well resolved, suggesting a flexible nature of this part (Fig. 1a). Of note, the cavity II exhibits an amphipathic environment (Fig. 2b). As a result, the $\mathrm{C}_{8}$ fatty acid chain of the octanoyl moiety sits on top of an extensive polar interaction network at the bottom of the cavity II including E124 $4^{3.33}$ and R283 ${ }^{6.55}$ while being capped by hydrophobic GHSR residues from the upper region of the cavity II (Fig. 2b). The acyl group of the octanoyl moiety sticks towards and likely interacts with the side chain of Q120 $0^{3.29}$ of GHSR. Previous mutagenesis studies showed that individual mutations of E124 $4^{3.33}$, R283 ${ }^{6.55}$ and Q120 ${ }^{3.29}$ to non-polar residues led to decreased potency of ghrelin ${ }^{34,37}$. We also showed that mutations of hydrophobic residues in the cavity II to larger or polar residues, which potentially disrupt the binding of the octanoyl moiety, resulted in compromised action of ghrelin (Fig. 2c), supporting our structural insights.

The non-peptide agonist ibutamoren also samples both cavity I and cavity II (Fig. 2d). It mainly occupies the bottom space of the ghrelin-binding pocket similar to the antagonist $\mathrm{C} 12$. The structures of ghrelin- and ibutamoren-bound GHSR share similar overall conformation with a root-mean-square deviation (RMSD) of the $\mathrm{C} \alpha$ atoms at $1.23 \AA$. Subtle structural differences can be observed at the upper region of the binding pocket including ECL2 and 3 (Extended Data Fig. S3a), likely caused by the binding of Leu5-Val12 of ghrelin in this region. The three arms of ibutamoren point towards three different directions, mimicking the first four residues of ghrelin, Gly1-Phe4, including the octanoyl moiety (Fig. 2d). The phenyl group of ibutamoren sits in the cavity II and forms hydrophobic interactions with surrounding hydrophobic residues $1178^{4.60}$, L181 4.63 and L210 5.36 of GHSR similarly to the octanoyl moiety of ghrelin (Fig. 2e). The other two arms of ibutamoren stick towards the bottom region of cavity II and the extracellular surface, respectively (Fig. 2e). Multiple hydrogen bonds are observed at the bottom of binding pocket between ibutamoren and GHSR residues D99 ${ }^{2.60}$, Q120 $0^{3.29}$, and R283 ${ }^{6.55}$ (Fig. 2e). Of note, the bottom region of cavity II exhibits a negatively charged environment to accommodate the smallest arm of ibutamoren with two amine groups (Extended Data Fig. S3b). The largest arm of ibutamoren containing an indoline-3,4'-piperidine ring structure forms hydrophobic and cation- $\pi$ interactions with the side chains of GHSR residues F286 6.58 and R102 2.63 , respectively. R102 2.63 also forms a hydrogen bond with a hydroxyl group attached to the indoline ring of ibutamoren. Mutations of hydrophobic residues in the cavity II caused similar functional consequences to both ibutamoren and ghrelin (Fig. 2f, Extended Data Fig. S3c). In addition, 
mutation of R102.63, which forms hydrogen bonding and cation- $\pi$ interactions with ibutamoren, resulted in compromised action of ibutamoren as well (Fig. 2f).

\section{Distinctive activation mechanism of GHSR}

GHSR adopts an active conformation in our structures, which is stabilized by the $\mathrm{G}_{\mathrm{i}}$ protein. Both extracellular and cytoplasmic regions of active GHSR showed significant structural differences compared to the inactive GHSR in the crystal structure reported before ${ }^{34}$. At the extracellular region, the most prominent difference observed lies in TM7 (Fig. 3a), which is unusual for class A GPCRs ${ }^{38}$. Compared to that in the inactive GHSR, the extracellular segment of TM7 in both active GHSR structures with ghrelin and ibutamoren extends by two more helical turns and moves towards TM6 (Fig. 3a). Such a large conformational change is not likely to be caused directly by agonist-binding since there is little interaction between TM7 and both agonists. We also observed a notable shift of the extracellular half of TM6 in the active GHSR in comparison with the inactive GHSR (Fig. 3a). In the core region of GHSR, we observed remarkable conformational changes of highly conserved residues V131 $1^{3.40}$, P224 ${ }^{5.50}, \mathrm{~F} 272^{6.44}$ and W276 6.48 (Fig. 3b). Conformational changes of these conserved residues especially the 'transmission switch' residues F272 2.44 and W276 ${ }^{6.48}$ have been suggested to link the extracellular agonist-binding to the cytoplasmic receptor activation and $G$ protein-coupling for class A GPCRs (Extended Data Fig. 4a) ${ }^{38-40}$. The cytoplasmic region of GHSR in our structures exhibits typical features of activated GPCRs including a large outward displacement of TM6 and an inward movement of TM7 (Fig. 3c) ${ }^{38}$. In addition, the cytoplasmic regions of TMs 1-4 together with ICL1 and ICL2 all showed notable movements. Surprisingly, the cytoplasmic region of TM5 in the inactive and active structures are almost identical (Fig. 3c). This is in contrast to most of other class A GPCRs, for which TM5 usually undergoes notable conformational changes at the cytoplasmic region during receptor activation ${ }^{38}$. Several residues in the middle region of TM5 from F22 $1^{5.47}$ to P224 $4^{5.50}$ do exhibit large conformational changes in the active GHSR compared to those in the inactive GHSR (Extended Data Fig. 4b). However, these changes do not translate to a significant displacement of the cytoplasmic region of TM5.

Our structural analysis suggested a receptor activation mechanism involving conformational changes of the salt bridge pair E124 $4^{3.33}$ and R283 $3^{6.55}$ and a unique structural motif underneath. Structural alignment of the ligand-binding pockets for the two agonists and the antagonist C12 suggests that agonist-binding causes a subtle change in the salt bridge between E124.33 and R283 ${ }^{6.55}$ (Fig. 4a). Specifically, the side chain of R283 $3^{6.55}$ moves towards F279 $9^{6.51}$ and H280 6.52 due to steric effects with the octanoyl chain of ghrelin or the phenyl group of ibutamoren (Figs.

4a and b). This conformational change further transduces through $\mathrm{F} 279^{6.51}$ and $\mathrm{H} 280^{6.52}$ to cause rearrangement of an aromatic cluster formed by residues W276 $6.48, \mathrm{~F} 279^{6.51}, \mathrm{H} 280^{6.52}$ and F312 7.42 (Fig. 4b). As a result, W276 $6^{6.48}$ toggles to further induce significant displacement of F272 $2^{6.44}$ and the cytoplasmic segment of TM6, resulting in the activation of GHSR (Fig. $4 \mathbf{b}$, Extended Data Fig. 4a). Such a notion of receptor activation was supported by previous 
mutagenesis studies, which showed that individual mutations of residues F279 ${ }^{6.51}$, F312 ${ }^{7.42}$ and $\mathrm{W} 276^{6.48}$ in the aromatic cluster significantly lowered the potency of ghrelin in activating GHSR 34,37 . Our proposed receptor activation mechanism also suggests that the conformation of a GHSR ligand around the E124 $4^{3.33}-\mathrm{R} 283^{6.55}$ salt bridge in the cavity II is an important structural determinant for ligand efficacy, providing a molecular foundation for designing novel ghrelin agonists.

\section{Dynamic nature of $\mathrm{G}_{\mathrm{i}}$-coupling to GHSR}

The $\mathrm{G}_{\mathrm{i}}$-coupling is almost identical in both structures of the GHSR-G $\mathrm{G}_{\mathrm{i}}$ complexes with two agonists. The major interaction site with GHSR is at the C-terminal half of $\alpha 5$ of $G \alpha_{i}$ (Fig. 5a and b). Hydrophobic residues I344, L348, L353 of $\mathrm{G} \alpha_{\mathrm{i}}$ line on one side of $\alpha 5$ to form hydrophobic interactions with GHSR residues $\mathrm{I} 145^{3.54}$, I235 5.61 , I239 5.65 and L265 6.37 (Fig. 5a). The side chains of N347 and D350 of $\mathrm{G}_{\mathrm{i}}$ engage in polar interactions with the main chain carbonyl of A144 and the side chain of K329 of GHSR, respectively (Fig. 5a and b). The side chain of R141.50 in the conserved $\mathrm{DR}^{3.50} \mathrm{Y}$ motif of GHSR also forms a hydrogen bond with the main chain carbonyl of C351 of $\mathrm{G}_{\mathrm{i}}$. In addition, F336, I343 and I344 in $\alpha 5$ and L194 in $\beta 2-\beta 3$ loop of G $\alpha_{i}$ pack against GHSR residues P148 and I149 in ICL2 to form another set of hydrophobic interactions at the receptor and $\mathrm{G} \alpha_{\mathrm{i}}$ interface (Fig. 5b). Besides $\mathrm{G} \alpha_{\mathrm{i}}, \mathrm{G}_{\beta}$ also directly interacts with GHSR through multiple polar interactions (Fig. 5a), similar to those observed in the structure of the formylpeptide 2 (FPR2)-G complex $^{41}$.

Despite distinctive ligand recognition and receptor activation mechanisms, the $\mathrm{G}_{\mathrm{i}}$-coupling mode of GHSR is highly similar to those of other closely related neuropeptide GPCRs such as

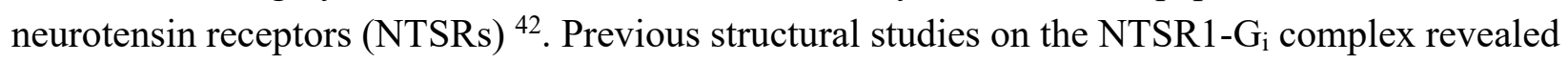
two conformational states of the complex, the canonical and non-canonical states ${ }^{43}$. Structural comparison indicates that the GHSR-G $\mathrm{G}_{i}$ complex in our structures resembles the canonical NTSR1$\mathrm{G}_{\mathrm{i}}$ state with a similar $\mathrm{G}_{\mathrm{i}}$ interaction profile (Fig. 6a). It is to be noted that our cryo-EM analysis also revealed minor structural classes of particles with different conformations besides the ghrelinand ibutamoren-GHSR-G $\mathrm{G}_{i}$ complexes with the 2.7-Å cryo-EM maps (Extended Data Fig. 1c). We assigned the conformation of the GHSR- $\mathrm{G}_{i}$ complex in the 2.7- $\AA$ structures as Conformer 1. 3D reconstruction using particles from one minor class of the ghrelin-GHSR-G $\mathrm{G}_{\mathrm{i}}$ complex yielded a 3.5- $\AA$ map of a second conformation, which we assigned as Conformer 2 (Extended Data Figs.

1c and 5). Structural comparison with Conformer 1 showed that there is a small but remarkable shift of the entire $G_{i}$ heterotrimer relative to the receptor with a $\sim 15^{\circ}$ rotation of the N-terminal $\alpha$ helix $(\alpha N)$ and $\sim 10^{\circ}$ rotation of the C-terminal $\alpha$-helix ( $\left.\alpha 5\right)$ of $G_{\alpha i}$ in Conformer 2 (Fig. 6b). Despite such differences in the orientation of $\mathrm{G}_{i}$, the structure of ghrelin-GHSR and the interactions between $\mathrm{G}_{\mathrm{i}}$ and GHSR stay largely unchanged in Conformer 2. Similar structural variations were also observed for the NTSR1-G $\mathrm{G}_{\mathrm{i}}$ complex at both canonical and non-canonical states ${ }^{43}$. Whether such dynamic nature of $\mathrm{G}_{\mathrm{i}}$-coupling is associated with other $\mathrm{G}_{\mathrm{i}}$-coupled GPCRs is not clear. Interestingly, similar to GHSR, NTSR1 is also able to couple to multiple G proteins besides $\mathrm{G}_{\mathrm{i}}{ }^{44}$. 
Both receptors lack critical structural elements for selective $\mathrm{G}_{\mathrm{i}}$-coupling, which may result in potentially multiple modes of $\mathrm{G}_{\mathrm{i}}$ recognition.

In summary, we report two cryo-EM structures of the GHSR-G $\mathrm{G}_{\mathrm{i}}$ complexes with ghrelin and ibutamoren. Our structures clearly reveal the ligand-binding pocket for ghrelin, where the peptide moiety of ghrelin mainly occupies cavity I while the octanoyl moiety adopts an extended conformation to occupy cavity II. Ibutamoren mimics the first four $\mathrm{N}$-terminal residues of ghrelin including the octanoyl moiety to bind at the bottom region of the ligand-binding pocket. Both agonists cause conformational changes of the salt bridge pair E124 $4^{3.33}$ and R283 $3^{6.55}$ and the aromatic cluster W276 6.48 , F279 $6.51, \mathrm{H} 280^{6.52}$ and F3127.42, which may in turn lead to GHSR activation. The overall conformation of the GHSR- $\mathrm{G}_{\mathrm{i}}$ complex in our structures highly resembles the canonical state of the NTSR1- $\mathrm{G}_{\mathrm{i}}$ complex. The variations of $\mathrm{G}_{\mathrm{i}}$-coupling observed for both GHSR and NTSR1 shed light on a potentially highly dynamic nature of $\mathrm{G}_{\mathrm{i}}$-coupling to GPCRs with a promiscuous $\mathrm{G}$ protein-coupling ability. 


\section{Acknowledgement}

We thank members of the Cryo-electron Microscopy and Tomography Center of St Jude Children's Research Hospital for help with cryo-EM data collection. J. S. is supported by the National Institutes of Health (NIH, HL143037) and American Lebanese Syrian Associated Charities (ALSAC). C.Z. is supported by NIH grants R35GM128641 and R03TR003306.

\section{Contributions}

H. L. performed protein expression and purification for cryo-EM studies and the calcium signaling assay. A.M. and J.S. performed cryo-EM data collection and processing. H.L., D.S., and C.Z. built the models and performed structure refinement. M.D. and J.B. performed the GTP turnover assay. H.L., S.J. and C.Z. supervised all studies, and C.Z wrote the manuscript with H.L., J.B., and J.S.

\section{Competing Interests}

The authors declare no competing financial interests.

\section{Data availability}

The 3D cryo-EM density maps have been deposited in the Electron Microscopy Data Bank under the accession numbers EMD-24267 for the ghrelin-GHSR-G $\mathrm{G}_{\mathrm{i}}$ complex and EMD-24268 for the ibutamoren-GHSR-G $\mathrm{G}_{\mathrm{i}}$ complex. Atomic coordinates for the atomic models of the ghrelin-GHSR$\mathrm{G}_{\mathrm{i}}$ and ibutamoren-GHSR- $\mathrm{G}_{\mathrm{i}}$ complexes have been deposited in the Protein Data Bank under the accession numbers 7NA7 and 7NA8, respectively. 

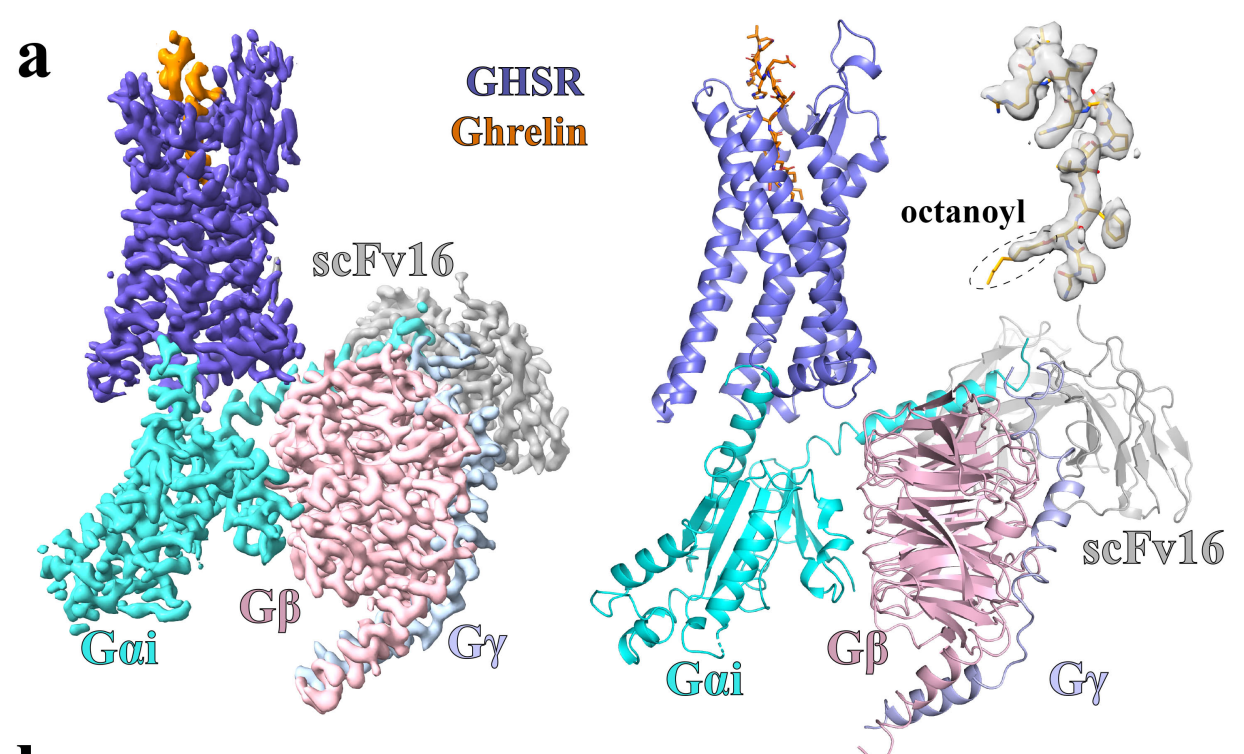

b

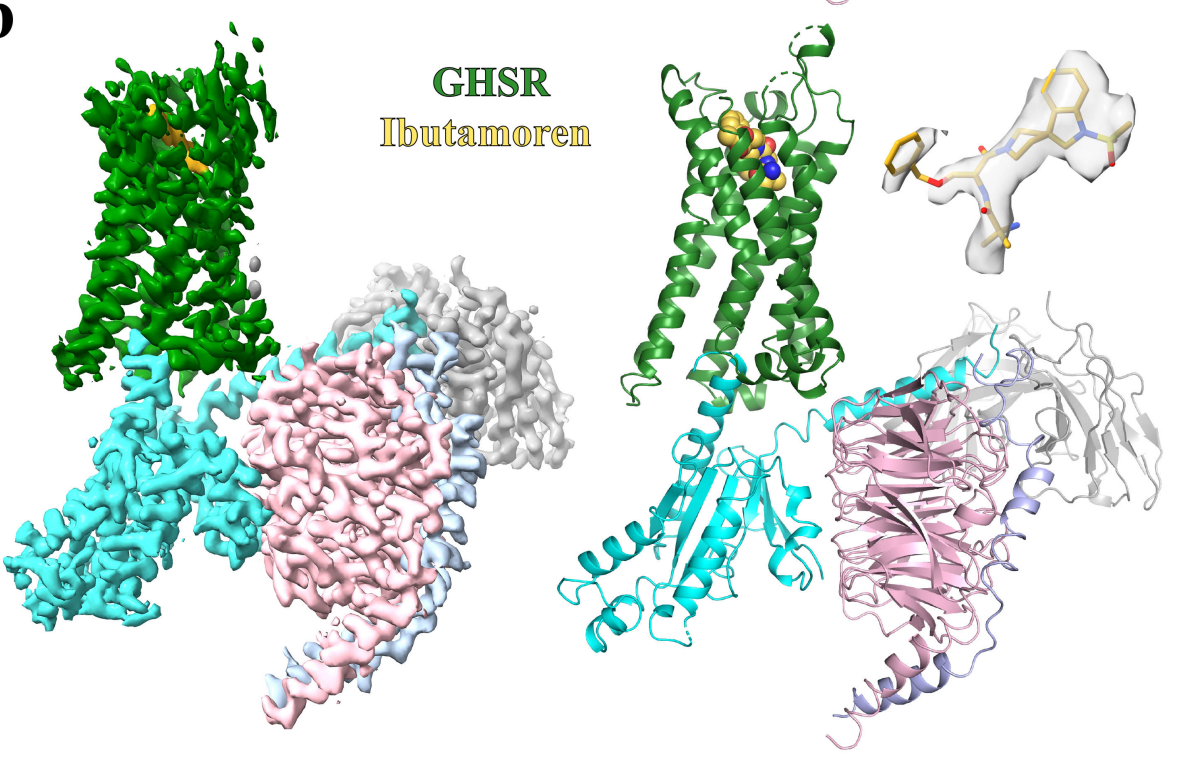

Figure 1. Overall structures of the GHSR-G $\mathbf{G}_{\mathbf{i}}$ complexes. (a) and (b) Cryo-EM density maps of the complex with ghrelin (orange) and ibutamoren (yellow) and overall structures. GHSR bound to ghrelin and ibutamoren is colored in blue and green, respectively. $G_{\alpha i}, G_{\beta}$ and $G_{\gamma}$ subunits are colored in cyan, pink and light blue, respectively. ScFv16 is colored in grey. The density maps of the two agonists are shown in light grey. The octanoyl group in ghrelin is circled. 


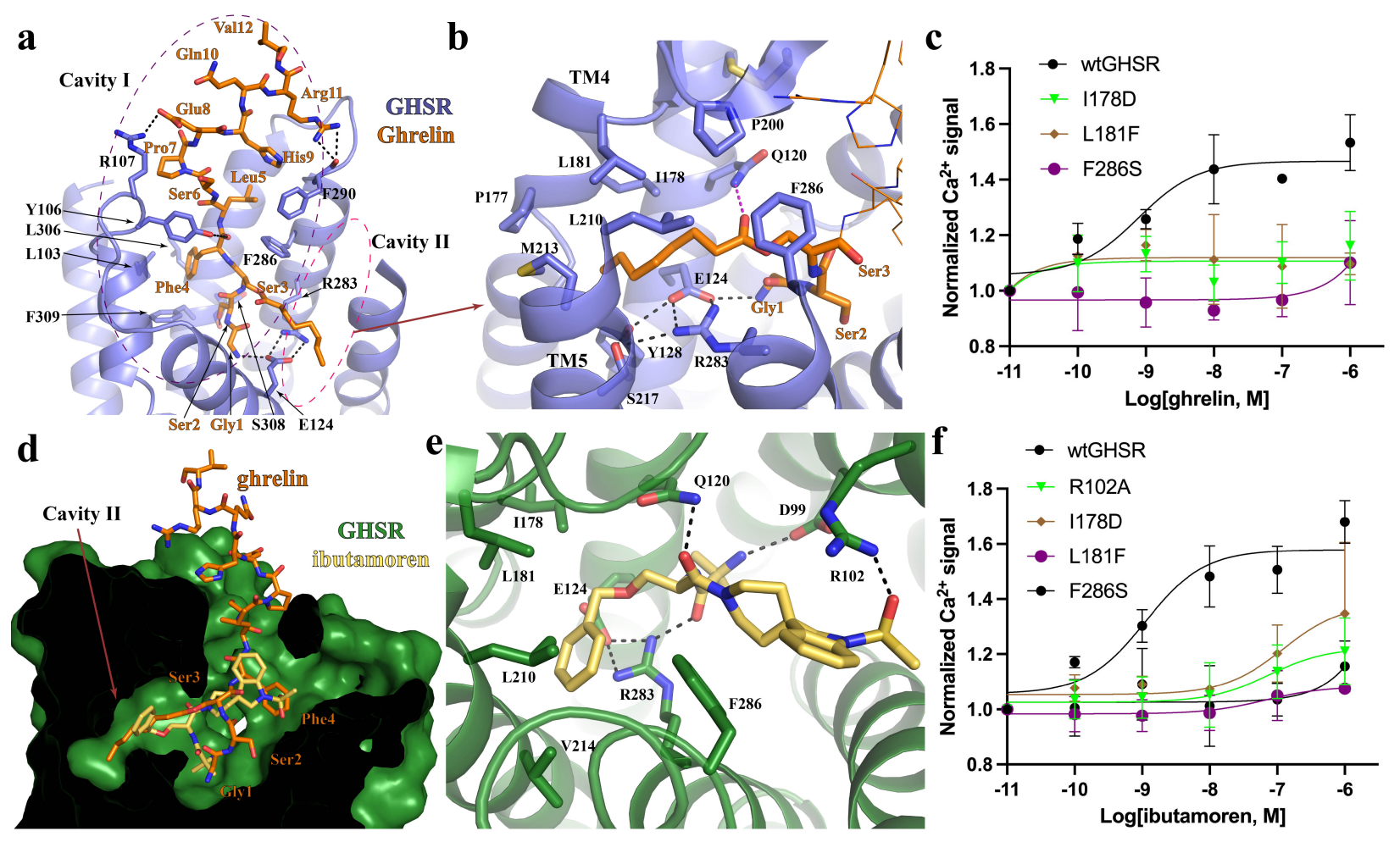

Figure 2. Binding pockets for ghrelin and ibutamoren. (a) Ghrelin binding in the cavity I and II. Ghrelin residues are labeled in orange. (b) Binding of the octanoyl group of ghrelin in the cavity II. (c) Dose-dependent action of ghrelin on the wild type GHSR (wtGHSR) and mutants. (d) Alignment of ghrelin and ibutamoren. (e) Ibutamoren binding pocket. (f) Dose-dependent action of ibutamoren on wtGHSR and mutants. In $\mathbf{c}$ and $\mathbf{f}$, agonist-induced GHSR signaling was measured by $\mathrm{Ca}^{2+}$ mobilization assay. Each data point represents Mean \pm S.D. from 3 independent assays. Polar interactions are shown as dashed lines in $\mathbf{a}, \mathbf{b}$ and $\mathbf{e .}$ 

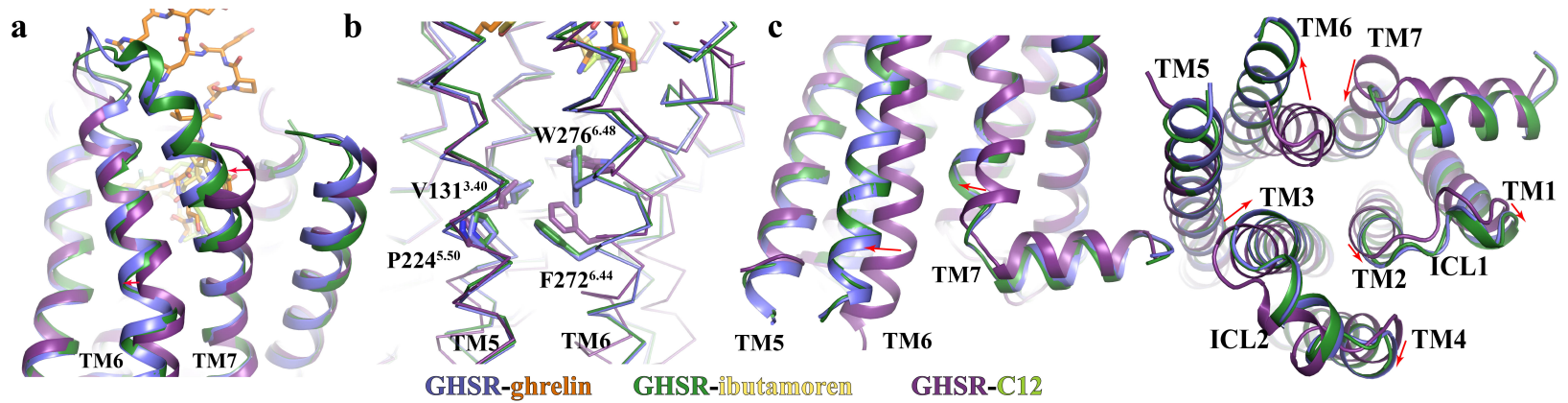

Figure 3. Active conformation of GHSR. Conformational changes of the extracellular regions of TM6 and TM7 (a), the highly conserved transmission switch residues (b), and cytoplasmic regions of TMs (c) in the active GHSR relative to them in the inactive GHSR. Two active GHSR bound to ghrelin and ibutamoren and the inactive GHSR bound to $\mathrm{C} 12$ are colored in blue, green and purple, respectively. Ghrelin, ibutamoren and C12 are shown as orange, yellow and lemon sticks, respectively. Red arrows indicate changes of residues or regions from inactive to active states. 


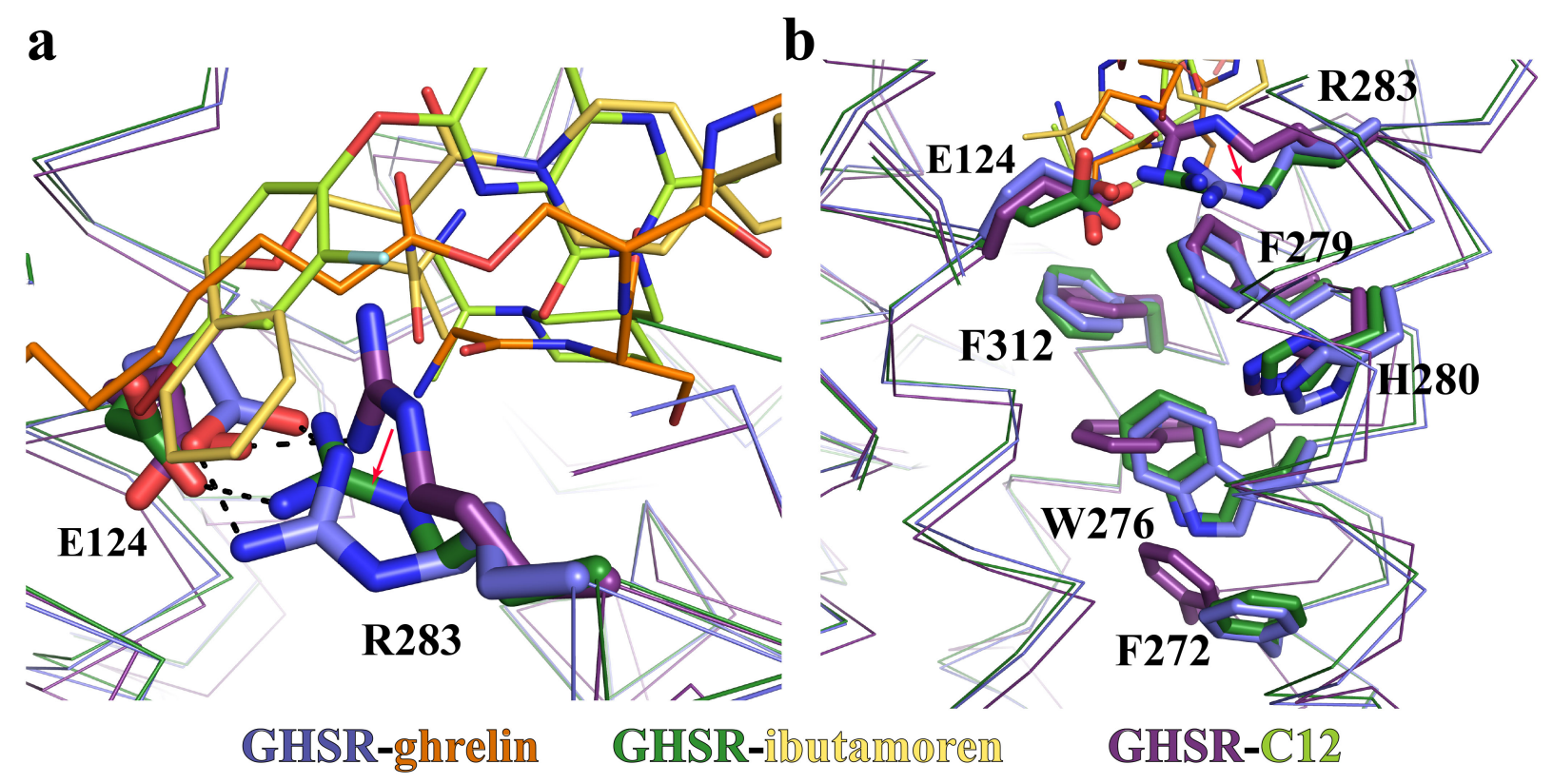

Figure 4. Conformational changes of critical motifs near the agonist-binding pocket. (a) Different conformations of the E124-R283 salt bridge in the active structures of GHSR with ghrelin and ibutamoren and the inactive structure of GHSR with C12. The salt bridge interactions are shown as dashed lines. (b) Rearrangement of the aromatic cluster residues W276, F279, H280 and F312 in the active and inactive GHSR. 


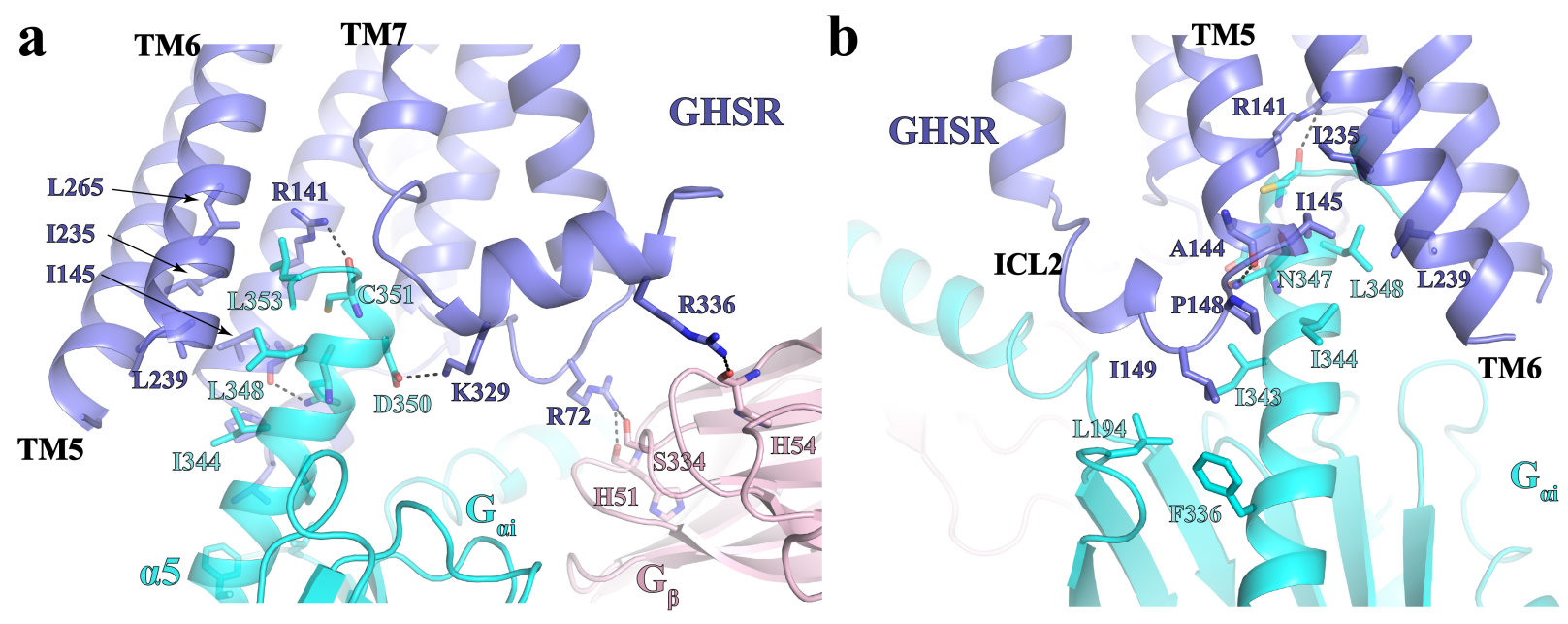

Figure 5. GHSR and $\mathbf{G}_{\mathbf{i}}$ binding interface. (a) and (b) Detailed interactions between GHSR and $\mathrm{G}_{\mathrm{i}}$ viewed from two angles. GHSR, $\mathrm{G}_{\alpha \mathrm{i}}$, and $\mathrm{G}_{\beta}$ are colored in blue, cyan and pink, respectively. Polar interactions are shown as dashed lines. 

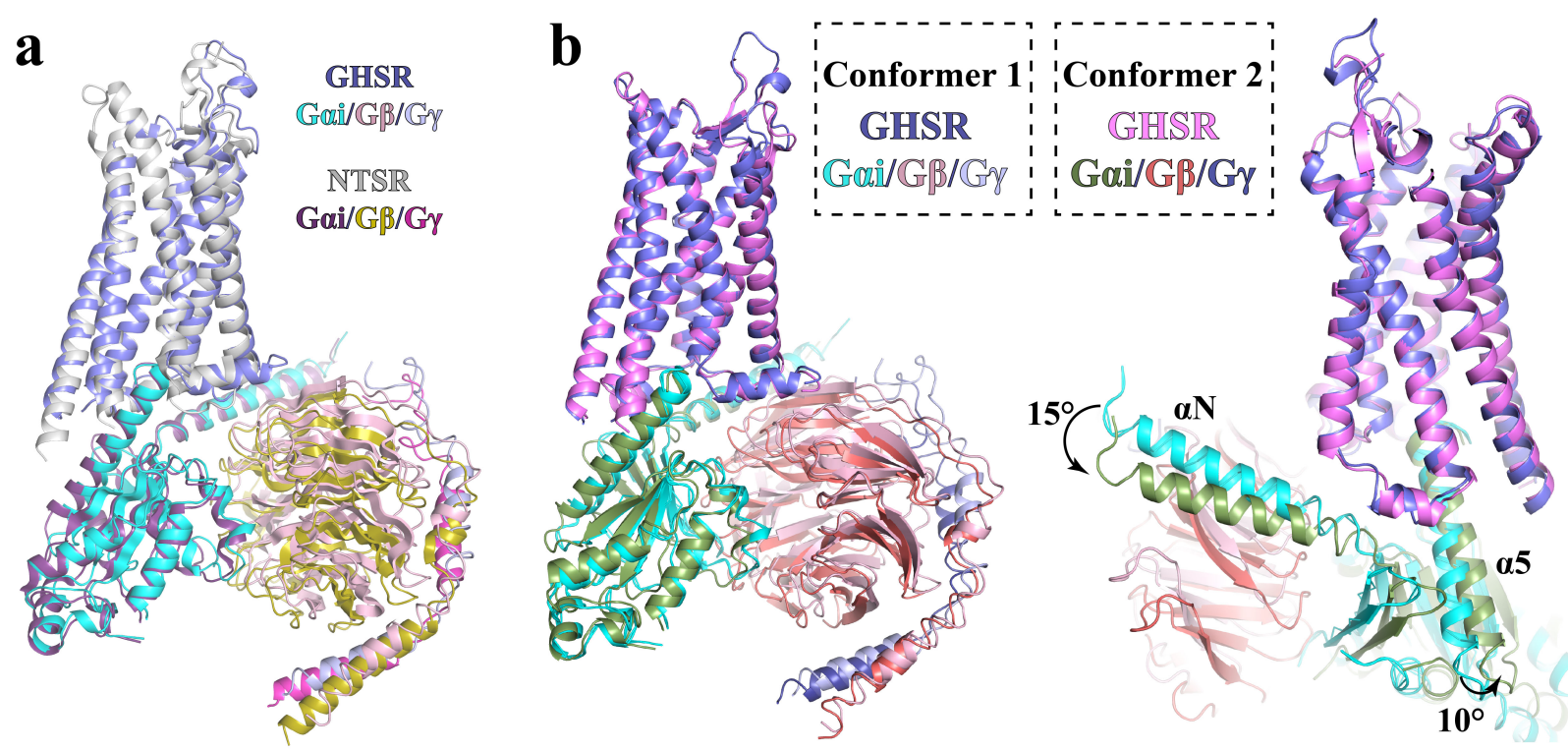

Figure 6. Structures of the ghrelin-GHSR-G ${ }_{i}$ complex in Conformer 1 and 2. (a) Structural alignment of the ghrelin-GHSR-G $\mathrm{G}_{\mathrm{i}}$ complex in Conformer 1 with the neurotensin-NTSR-G $\mathrm{G}_{\mathrm{i}}$ complex in the canonical state (PDB ID 6OS9). The $\mathrm{G}_{\mathrm{i}}$-coupling mode is highly similar. (b) Structural alignment of the ghrelin-GHSR-G $G_{i}$ complex in Conformer 1 and 2. 


\section{Materials and Methods}

\section{GHSR expression and purification}

The coding sequence of wild-type human ghrelin receptor (GHSR) was cloned into pFastbac (ThermoFisher) with an $\mathrm{N}$ terminal Flag tag followed by a peptide sequence corresponding to the $\mathrm{N}$-terminal fragment of the human $\beta_{2}$-adrenergic receptor to increase its expression. The protein was expressed in Sf9 insect cells (Invitrogen) using the Bac-to-Bac baculovirus expression system (ThermoFisher). 1L cells were lysed by stirring in buffer containing $20 \mathrm{mM}$ Tris-HCl, pH7.5, 0.2 $\mu \mathrm{g} / \mathrm{ml}$ leupeptin, $100 \mu \mathrm{g} / \mathrm{ml}$ benzamidine and $1 \mu \mathrm{M}$ PF-05190457 (GHSR antagonist) (Tocris). Cell membranes were isolated by centrifugation at $25,000 \mathrm{~g}$ for $40 \mathrm{~min}$. Then the pellet was solubilized in buffer containing $20 \mathrm{mM}$ HEPES, pH 7.5, $750 \mathrm{mM} \mathrm{NaCl}, 1 \%$ (w/v) n-dodecyl-b-Dmaltoside (DDM, Anatrace), 0.2\% (w/v) sodium cholate (Sigma), 0.1\% (w/v) cholesterol hemisuccinate (CHS, Anatrace), 20\% (v/v) glycerol, $0.2 \mu \mathrm{g} / \mathrm{ml}$ leupeptin, $100 \mu \mathrm{g} / \mathrm{ml}$ benzamidine, 500 unit Salt Active Nuclease (Arcticzymes) and $1 \mu \mathrm{M} \mathrm{PF}-05190457$ at $4^{\circ} \mathrm{C}$ for $3 \mathrm{~h}$. Insoluble material was separated by centrifugation at 25,000 g for $40 \mathrm{~min}$. The supernatant was incubated with nickel Sepharose resin (GE healthcare) plus $15 \mathrm{mM}$ imidazole at $4{ }^{\circ} \mathrm{C}$ overnight. The resin was washed with 5 column volume of buffer containing $20 \mathrm{mM}$ HEPES, pH 7.5, $500 \mathrm{mM} \mathrm{NaCl}$, $0.1 \%$ (w/v) DDM, 0.02\% (w/v) CHS, $25 \mathrm{mM}$ imidazole and $1 \mu \mathrm{M}$ PF-05190457. The protein was eluted with buffer containing $20 \mathrm{mM}$ HEPES, pH 7.5, $500 \mathrm{mM} \mathrm{NaCl}, 0.1 \%$ (w/v) DDM, 0.02\% (w/v) CHS, $400 \mathrm{mM}$ imidazole and $1 \mu \mathrm{M}$ PF-05190457 and loaded onto anti-Flag M1 antibody resin (homemade) after adding $2 \mathrm{mM} \mathrm{CaCl}_{2}$. The detergent was slowly exchanged to $0.01 \%$ (w/v) lauryl maltose neopentyl glycol (MNG, Anatrace) containing $1 \mu \mathrm{M}$ ghrelin (Tocris) or MK0677 (Tocris) on the M1 antibody resin. The protein was finally eluted with buffer containing $20 \mathrm{mM}$ HEPES, pH 7.5, $100 \mathrm{mM} \mathrm{NaCl}, 0.002 \%$ (w/v) MNG, 0.001\% (w/v) CHS, $200 \mathrm{mg} / \mathrm{ml}$ Flag peptide, $5 \mathrm{mM}$ EDTA and $1 \mu \mathrm{M}$ ghrelin or $\mathrm{MK}-0677$, and further purified by size-exclusion chromatography using a Superdex 200 Increase column (Cytiva). The receptor was collected and concentrated to $5 \mathrm{mg} / \mathrm{ml}$ using 100-kDa molecular weight cut-off concentrators (Millipore) for complex assembly.

\section{Expression and purification of $G_{i}$ heterotrimer}

The wild-type $\mathrm{G}_{\alpha \mathrm{i} 1}$ was cloned in pFastBac vector without any tag, and the virus was prepared using Bac-to-Bac system (Invitrogen). N-terminal $6 \times$ His-tagged human $\mathrm{G}_{\beta 1}$, and human $\mathrm{G}_{\gamma 2}$ were cloned into pVL1392 vector, and the virus was prepared using the BestBac system (Expression Systems). The heterotrimeric Gi complex was expressed in Sf9 insect cells by co-expressing all three subunits. Cells at a density of $4 \times 10^{6} / \mathrm{ml}$ were infected with both $\mathrm{G}_{\alpha i}$ and $\mathrm{G}_{\beta \gamma}$ virus at ratios of $20 \mathrm{ml}$ and $1 \mathrm{ml}$ per liter, respectively, at $27^{\circ} \mathrm{C}$ for 48 hours before harvesting. Cells were lysed in lysis buffer containing $10 \mathrm{mM}$ Tris, $\mathrm{pH} 7.5,100 \mu \mathrm{M} \mathrm{MgCl}_{2}, 5 \mathrm{mM} \beta$-mercaptoethanol ( $\beta$-ME), $10 \mu \mathrm{M}$ GDP, $0.2 \mu \mathrm{g} / \mathrm{ml}$ leupeptin and $150 \mu \mathrm{g} / \mathrm{ml}$ benzamidine. The cell membrane was collected by centrifugation at $25,000 \mathrm{~g}$ for $30 \mathrm{~min}$ at $4{ }^{\circ} \mathrm{C}$. Cell membranes were solubilized in solubilization 
buffer containing 20mM HEPES pH 7.5, $100 \mathrm{mM} \mathrm{NaCl}, 1 \%$ sodium cholate, $0.05 \%$ DDM, $5 \mathrm{mM}$ $\mathrm{MgCl}_{2}, 2 \mu \mathrm{L}$ CIP, $5 \mathrm{mM} \beta$-ME, $10 \mu \mathrm{M}$ GDP, $10 \%$ glycerol, $0.2 \mu \mathrm{g} / \mathrm{ml}$ leupeptin and $150 \mu \mathrm{g} / \mathrm{ml}$ benzamidine. The supernatant was separated by centrifugation at $25,000 \mathrm{~g}$ for $30 \mathrm{~min}$ and incubated with nickel resin in batch for 1 hour at $4{ }^{\circ} \mathrm{C}$. The resin was then washed in batch with solubilization buffer and transferred to a gravity column. The buffer was exchanged on column from solubilization buffer to wash buffer comprised of $20 \mathrm{mM}$ HEPES pH 7.5, $50 \mathrm{mM} \mathrm{NaCl}, 0.1 \%$ DDM, $1 \mathrm{mM} \mathrm{MgCl}$, $5 \mathrm{mM} \beta$-ME, $10 \mu \mathrm{M}$ GDP, $0.2 \mu \mathrm{g} / \mathrm{ml}$ leupeptin and $150 \mu \mathrm{g} / \mathrm{ml}$ benzamidine. The protein was eluted in wash buffer with $250 \mathrm{mM}$ imidazole and treated with Lamda Phosphatase (New England BioLab) and Alkaline Phosphatase (New England BioLab) overnight at $4{ }^{\circ} \mathrm{C}$. The protein was further purified with anion exchange chromatography. The low salt buffer was comprised of $20 \mathrm{mM}$ HEPES pH 7.5, $40 \mathrm{mM} \mathrm{NaCl}, 0.1 \%$ DDM, $1 \mathrm{mM} \mathrm{MgCl} 2,100$ $\mu \mathrm{M}$ TCEP, $10 \mu \mathrm{M}$ GDP. The high salt buffer was prepared by adding $1 \mathrm{M} \mathrm{NaCl}$ to the low salt buffer. The pure $\mathrm{G}_{\mathrm{i}}$ with an appropriate stoichiometry of three subunits was the supplemented by $10 \%$ glycerol, concentrated to $\sim 20 \mathrm{mg} / \mathrm{ml}$, flash-frozen in liquid nitrogen, and stored at $-80{ }^{\circ} \mathrm{C}$.

\section{Assembly of GHSR-G G $_{\text {i }}$ complexes}

Purified GHSR was mixed with $\mathrm{G}_{\mathrm{i}}$ heterotrimer at a 1:1.2 molar ratio. The coupling reaction was initiated by incubation at $25^{\circ} \mathrm{C}$ for 1 hour and was followed by addition of Apyrase (New England BioLab) to catalyze the hydrolysis of GDP overnight at $4^{\circ} \mathrm{C}$. This was to form the stable nucleotide-free complex. To remove the excess $G_{i}$ protein, the mixture was further purified with anti-Flag M1 antibody resin. The complex was eluted using the buffer comprised of $20 \mathrm{mM}$ HEPES pH 7.5, $100 \mathrm{mM} \mathrm{NaCl}, 0.01 \% \mathrm{MNG}, 0.001 \% \mathrm{CHS}, 1 \mu \mathrm{M}$ ghrelin or MK-0677, $200 \mu \mathrm{g} / \mathrm{ml}$ Flag peptide. Finally, a 1.2 molar excess of scFV16 was added to the elution. The GHSR-GiscFV16 complex was purified and buffer-exchanged by size exclusion chromatography with buffer containing $20 \mathrm{mM}$ HEPES pH 7.5, $100 \mathrm{mM} \mathrm{NaCl}, 0.002 \% \mathrm{MNG}, 0.001 \%$ CHS and $1 \mu \mathrm{M}$ ghrelin or MK-0677. Peak fractions were concentrated to $\sim 7 \mathrm{mg} / \mathrm{ml}$ for cryo-EM data collection.

\section{Cryo-EM data collection, processing, model building and refinement}

Cryo-EM grids were prepared with a Vitrobot Mark IV (FEI). Quantifoil R1.2/1.3 holey carbon gold grids (SPI) were glow-discharged for 30s. Then $3.5 \mu \mathrm{L}$ of $7 \mathrm{mg} / \mathrm{ml}$ protein sample was pipetted onto the grids, which were blotted for 3 s under blot force -3 at $100 \%$ humidity and frozen in liquid nitrogen cooled liquid ethane. The grids were loaded onto a $300 \mathrm{keV}$ Titan Krios (FEI) with a K3 direct electron detector (Gatan) and an energy filter.

Images of the ghrelin-GHSR-G $\mathrm{G}_{\mathrm{i}}$ complex dataset were recorded with SerialEM 45 in superresolution mode with a pixel size of $0.649 \AA$ and a defocus range of -0.8 to $-1.6 \mu \mathrm{m}$. Movies were recorded during a $2.1 \mathrm{~s}$ exposure with $30 \mathrm{~ms}$ subframes (70 total frames) at a dose rate of 1.176 $\mathrm{e} / \AA^{2} /$ frame. The dataset with the MK0677-GHSR-G $\mathrm{G}_{\mathrm{i}}$ complex was collected with a pixel size of $0.826 \AA$ and a defocus range of -0.8 to $-1.6 \mu \mathrm{m}$. Movies were recorded during a $3 \mathrm{~s}$ exposure with $50 \mathrm{~ms}$ subframes (60 total frames) at a dose rate of $1.35 \mathrm{e} / \AA^{2} /$ frame. 
Both datasets were processed in cryoSPARC ${ }^{46}$ using a similar strategy (Extended Data Fig. 1c and d). Briefly, super-resolution image stacks were gain-normalized, binned by 2 with Fourier cropping, and corrected for beam-induced motion using MotionCor $2{ }^{47}$. Contrast transfer function (CTF) parameters were estimated from motion-corrected images using GCTF ${ }^{48}$. Following multiple rounds of 2D classification, ab initio reconstruction was performed in cryoSPARC asking for four classes, which resulted in one good class and three "trash" classes. Then multiple rounds of heterogenous refinement were performed against the four ab initio models to remove bad particles. Following the CTF refinement and non-uniform (NU) refinement, one last round of heterogenous refinement was carried out using three identical initial models (output of NU refinement). The heterogeneous refinement yielded two slightly different conformations, which were further refined by NU refinement. Resolutions were estimated using the 'gold standard' criterion ( $\mathrm{FSC}=0.143$ ), and local resolution was calculated in cryoSPARC.

The coordinates of NTSR, $\mathrm{G}_{\mathrm{i}}$ and $\mathrm{scFv} 16$ from the structure of the neurotensin-NTSR-Gi-scFv16 complex (PDB ID 6OS9) were used as initial models to dock into the cryo-EM maps using Chimera $^{49}$. The structures of GHSR- $G_{i}$ with both agonists were then built by iterative manual building and adjustment in $\operatorname{Coot}^{50}$ and real-space refinement in Phenix ${ }^{51}$. The final models were validated by Molprobity ${ }^{52}$. Data collection, processing and structure refinement statistics are listed in the Extended Data Table 1.

\section{Calcium mobilization assay}

Calcium mobilization assay to measure GHSR signaling was carried out in HEK-293T cells cultured in DMEM supplemented with $10 \%$ (vol/vol) FBS (Fisher Scientific). The cDNAs encoding human GHSR was cloned into the pcDNA3.1(+) vector (Invitrogen) with a FLAG peptide fused to the $\mathrm{N}$ terminus. Mutant variants were then generated by site-directed mutagenesis and all mutants were fully sequenced. Various GHSR constructs were transfected to HEK-293T cells using FuGENE Transfection Reagent (Promega). The surface expression of wtGHSR and various mutants in HEK-293T cells was determined and confirmed using FACS with a fluorescent FLAG M1 antibody (homemade).

To measure the agonist-induced calcium release, $50 \mu \mathrm{L}$ dye loading buffer made of Hank's Balanced Salt Solution (HBSS) with $5 \mu \mathrm{M}$ Fluo-4 (Sigma), 0.2\% pluronicacid and 1\% FBS was added to the GHSR-expressing cells and incubated for $1 \mathrm{~h}$ at $37^{\circ} \mathrm{C}$. Cells were then washed twice with HBSS buffer and left at room temperature in $50 \mu \mathrm{L}$ HBBS. Fluo-4 fluorescence intensity (excitation $480 \mathrm{~nm}$, emission $520 \mathrm{~nm}$ ) was measured as an indicator of calcium release in a multimode reader (Spark 20 M, TECAN). For the concentration-dependent responses of ghrelin or MK-0677, $50 \mu \mathrm{L}$ HBSS buffer containing different concentrations of ligand was injected to each well, and fluorescence was measured constantly in real time for $90 \mathrm{~s}$. The data were analyzed in GraphPad Prism 8 using the one site dose-response stimulation method. Results were presented as Mean \pm S.D. from 3 independent experiments. 


\section{GTP turnover assay}

Human GHSR was expressed in E. coli inclusion bodies, folded in amphipol A8-35 and then inserted into lipid nanodiscs formed with MSP1E3D1 and POPC:POPG (3:2 molar ratio) containing or not $10 \%$ cholesterol, as described in Damian et al ${ }^{53}$. After insertion into nanodiscs, active receptor fractions were purified using affinity chromatography with the biotinylated version of the JMV2959 antagonist immobilized on a streptavidin column ${ }^{33}$. GHSR containing discs were separated from aggregates and possible trace amounts of ligand through a size-exclusion chromatography step on a Superdex 200 increase 10/300 GL column (GE Healthcare) using a 25 mM Na-HEPES, $150 \mathrm{mM} \mathrm{NaCl}, 0.5 \mathrm{mM}$ EDTA, pH 7.5 buffer as the eluent. GTP turnover was assessed as described previously ${ }^{54}$. All experiments were carried out at $15^{\circ} \mathrm{C}$. The receptor was first incubated with the isolated $\mathrm{G}$ protein and, when applicable, the ligand $(10 \mu \mathrm{M})$ for 30 minutes in a $25 \mathrm{mM}$ HEPES, $100 \mathrm{mM} \mathrm{NaCl}, 5 \mathrm{mM} \mathrm{MgCl} 2$, pH 7.5 buffer. GTP turnover was then started by adding GTP $(5 \mu \mathrm{M})$ and GDP $(10 \mu \mathrm{M})$, and the amount of remaining GTP was assessed after 10 minutes incubation at $15^{\circ} \mathrm{C}$ using the GTPase-Glo assay (Promega). The signal was normalized in each case to that in the absence of receptor $(100 \%)$. 


\section{References}

1 Müller, T. D. et al. Ghrelin. Molecular Metabolism 4, 437-460, doi:10.1016/j.molmet.2015.03.005 (2015).

2 Mani, B. K. \& Zigman, J. M. Ghrelin as a Survival Hormone. Trends Endocrinol Metab 28, 843-854, doi:10.1016/j.tem.2017.10.001 (2017).

3 Abizaid, A. \& Hougland, J. L. Ghrelin Signaling: GOAT and GHS-R1a Take a LEAP in Complexity. Trends Endocrinol Metab 31, 107-117, doi:10.1016/j.tem.2019.09.006 (2020).

4 Davenport, A. P. et al. International Union of Pharmacology. LVI. Ghrelin receptor nomenclature, distribution, and function. Pharmacological reviews 57, 541-546 (2005).

5 Lutter, M. et al. The orexigenic hormone ghrelin defends against depressive symptoms of chronic stress. Nature neuroscience 11, $752-753$ (2008).

6 Spencer, S. J. et al. Ghrelin regulates the hypothalamic-pituitary-adrenal axis and restricts anxiety after acute stress. Biological psychiatry 72, 457-465 (2012).

7 Cone, J. J., McCutcheon, J. E. \& Roitman, M. F. Ghrelin acts as an interface between physiological state and phasic dopamine signaling. J Neurosci 34, 4905-4913, doi:10.1523/JNEUROSCI.4404-13.2014 (2014).

8 Kern, A. et al. Hippocampal Dopamine/DRD1 Signaling Dependent on the Ghrelin Receptor. Cell 163, 1176-1190, doi:10.1016/j.cell.2015.10.062 (2015).

9 Collden, G., Tschop, M. H. \& Muller, T. D. Therapeutic Potential of Targeting the Ghrelin Pathway. Int J Mol Sci 18, doi:10.3390/ijms18040798 (2017).

10 Lee, M. R. et al. The novel ghrelin receptor inverse agonist PF-5190457 administered with alcohol: preclinical safety experiments and a phase $1 \mathrm{~b}$ human laboratory study. Molecular psychiatry 25, 461-475 (2020).

11 Lee, M. R. et al. The novel ghrelin receptor inverse agonist PF-5190457 administered with alcohol: preclinical safety experiments and a phase $1 \mathrm{~b}$ human laboratory study. Mol Psychiatry 25, 461-475, doi:10.1038/s41380-018-0064-y (2020).

12 Zhang, H. \& Garcia, J. M. Anamorelin hydrochloride for the treatment of canceranorexia-cachexia in NSCLC. Expert opinion on pharmacotherapy 16, 1245-1253 (2015).

13 Murray, C. D. et al. Ghrelin enhances gastric emptying in diabetic gastroparesis: a double blind, placebo controlled, crossover study. Gut 54, 1693-1698 (2005).

14 Shin, A. et al. The ghrelin agonist RM-131 accelerates gastric emptying of solids and reduces symptoms in patients with type 1 diabetes mellitus. Clinical Gastroenterology and Hepatology 11, 1453-1459. e1454 (2013).

15 Shin, A. et al. Randomized controlled phase Ib study of ghrelin agonist, RM-131, in type 2 diabetic women with delayed gastric emptying: pharmacokinetics and pharmacodynamics. Diabetes care 36, 41-48 (2013).

16 Zatorski, H., Mosinska, P., Storr, M. \& Fichna, J. Relamorelin and other ghrelin receptor agonists-future options for gastroparesis, functional dyspepsia and proton pump inhibitors-resistant non-erosive reflux disease. J Physiol Pharmacol 68, 797-805 (2017).

17 Adunsky, A. et al. MK-0677 (ibutamoren mesylate) for the treatment of patients recovering from hip fracture: a multicenter, randomized, placebo-controlled phase IIb study. Arch Gerontol Geriatr 53, 183-189, doi:10.1016/j.archger.2010.10.004 (2011).

18 Sigalos, J. T. \& Pastuszak, A. W. The Safety and Efficacy of Growth Hormone Secretagogues. Sex Med Rev 6, 45-53, doi:10.1016/j.sxmr.2017.02.004 (2018). 
19 Bright, G. M., Do, M. T., McKew, J. C., Blum, W. F. \& Thorner, M. O. Development of a Predictive Enrichment Marker for the Oral GH Secretagogue LUM-201 in Pediatric Growth Hormone Deficiency. J Endocr Soc 5, bvab030, doi:10.1210/jendso/bvab030 (2021).

20 Patchett, A. et al. Design and biological activities of L-163,191 (MK-0677): a potent, orally active growth hormone secretagogue. Proceedings of the National Academy of Sciences 92, 7001-7005 (1995).

21 Müller, T. D. et al. Ghrelin. Molecular metabolism 4, 437-460 (2015).

22 Gutierrez, J. A. et al. Ghrelin octanoylation mediated by an orphan lipid transferase. Proceedings of the National Academy of Sciences 105, 6320-6325 (2008).

23 Yang, J., Brown, M. S., Liang, G., Grishin, N. V. \& Goldstein, J. L. Identification of the acyltransferase that octanoylates ghrelin, an appetite-stimulating peptide hormone. Cell 132, 387-396 (2008).

24 Hedegaard, M. A. \& Holst, B. The Complex Signaling Pathways of the Ghrelin Receptor. Endocrinology 161, doi:10.1210/endocr/bqaa020 (2020).

25 Dezaki, K., Kakei, M. \& Yada, T. Ghrelin uses Gai2 and activates voltage-dependent K+ channels to attenuate glucose-induced $\mathrm{Ca} 2+$ signaling and insulin release in islet $\beta$-cells: novel signal transduction of ghrelin. Diabetes 56, 2319-2327 (2007).

26 Mende, F. et al. Translating biased signaling in the ghrelin receptor system into differential in vivo functions. Proc Natl Acad Sci U S A 115, E10255-E10264, doi:10.1073/pnas.1804003115 (2018).

27 Nagi, K. \& Habib, A. M. Biased signaling: A viable strategy to drug ghrelin receptors for the treatment of obesity. Cell Signal 83, 109976, doi:10.1016/j.cellsig.2021.109976 (2021).

28 Mear, Y., Enjalbert, A. \& Thirion, S. GHS-R1a constitutive activity and its physiological relevance. Front Neurosci 7, 87, doi:10.3389/fnins.2013.00087 (2013).

29 Pantel, J. et al. Loss of constitutive activity of the growth hormone secretagogue receptor in familial short stature. J Clin Invest 116, 760-768, doi:10.1172/JCI25303 (2006).

$30 \mathrm{Ge}, \mathrm{X}$. et al. LEAP2 Is an Endogenous Antagonist of the Ghrelin Receptor. Cell Metabolism 27, 461-469.e466, doi:10.1016/j.cmet.2017.10.016 (2018).

31 Srisai, D. et al. MRAP2 regulates ghrelin receptor signaling and hunger sensing. Nature communications 8, 1-10 (2017).

32 Bender, B. J. et al. Structural Model of Ghrelin Bound to its G Protein-Coupled Receptor. Structure 27, 537-544 e534, doi:10.1016/j.str.2018.12.004 (2019).

33 Ferre, G. et al. Structure and dynamics of G protein-coupled receptor-bound ghrelin reveal the critical role of the octanoyl chain. Proc Natl Acad Sci U S A 116, 17525 17530, doi:10.1073/pnas.1905105116 (2019).

34 Shiimura, Y. et al. Structure of an antagonist-bound ghrelin receptor reveals possible ghrelin recognition mode. Nature Communications 11, 4160-4169, doi:10.1038/s41467020-17554-1 (2020).

35 Koehl, A. et al. Structure of the micro-opioid receptor-Gi protein complex. Nature 558, 547-552, doi:10.1038/s41586-018-0219-7 (2018).

36 Ballesteros, J. A. \& Weinstein, H. Integrated methods for the construction of threedimensional models and computational probing of structure-function relations in $\mathrm{G}$ protein-coupled receptors. Methods in Neurosciences 25, 366-428, doi:https://doi.org/10.1016/S1043-9471(05)80049-7 (1995). 
37 Holst, B. et al. Common structural basis for constitutive activity of the ghrelin receptor family. Journal of Biological Chemistry 279, 53806-53817 (2004).

38 Zhou, Q. et al. Common activation mechanism of class A GPCRs. Elife 8, doi:10.7554/eLife.50279 (2019).

39 Weis, W. I. \& Kobilka, B. K. The Molecular Basis of G Protein-Coupled Receptor Activation. Annu Rev Biochem 87, 897-919, doi:10.1146/annurev-biochem-060614033910 (2018).

40 Manglik, A. \& Kruse, A. C. Structural Basis for G Protein-Coupled Receptor Activation. Biochemistry 56, 5628-5634, doi:10.1021/acs.biochem.7b00747 (2017).

41 Zhuang, Y. et al. Structure of formylpeptide receptor 2-Gi complex reveals insights into ligand recognition and signaling. Nat Commun 11, 885, doi:10.1038/s41467-020-14728-9 (2020).

42 Fredriksson, R., Lagerstrom, M. C., Lundin, L. G. \& Schioth, H. B. The G-proteincoupled receptors in the human genome form five main families. Phylogenetic analysis, paralogon groups, and fingerprints. Mol Pharmacol 63, 1256-1272, doi:10.1124/mol.63.6.1256 (2003).

43 Kato, H. E. et al. Conformational transitions of a neurotensin receptor 1-Gil complex. Nature 572, 80-85, doi:10.1038/s41586-019-1337-6 (2019).

44 Besserer-Offroy, E. et al. The signaling signature of the neurotensin type 1 receptor with endogenous ligands. Eur J Pharmacol 805, 1-13, doi:10.1016/j.ejphar.2017.03.046 (2017).

45 Mastronarde, D. N. Automated electron microscope tomography using robust prediction of specimen movements. J Struct Biol 152, 36-51, doi:10.1016/j.jsb.2005.07.007 (2005).

46 Punjani, A., Rubinstein, J. L., Fleet, D. J. \& Brubaker, M. A. cryoSPARC: algorithms for rapid unsupervised cryo-EM structure determination. Nat Methods 14, 290-296, doi:10.1038/nmeth.4169 (2017).

47 Zheng, S. Q. et al. MotionCor2: anisotropic correction of beam-induced motion for improved cryo-electron microscopy. Nat Methods 14, 331-332, doi:10.1038/nmeth.4193 (2017).

48 Zhang, K. Gctf: Real-time CTF determination and correction. J Struct Biol 193, 1-12, doi:10.1016/j.jsb.2015.11.003 (2016).

49 Pettersen, E. F. et al. UCSF Chimera--a visualization system for exploratory research and analysis. J Comput Chem 25, 1605-1612, doi:10.1002/jcc.20084 (2004).

50 Emsley, P., Lohkamp, B., Scott, W. G. \& Cowtan, K. Features and development of Coot. Acta Crystallogr D Biol Crystallogr 66, 486-501, doi:10.1107/S0907444910007493 (2010).

51 Adams, P. D. et al. PHENIX: a comprehensive Python-based system for macromolecular structure solution. Acta Crystallogr D Biol Crystallogr 66, 213-221, doi:10.1107/S0907444909052925 (2010).

52 Chen, V. B. et al. MolProbity: all-atom structure validation for macromolecular crystallography. Acta Crystallogr D Biol Crystallogr 66, 12-21, doi:10.1107/S0907444909042073 (2010).

53 Damian, M. et al. High constitutive activity is an intrinsic feature of ghrelin receptor protein: a study with a functional monomeric GHS-R1a receptor reconstituted in lipid discs. J Biol Chem 287, 3630-3641, doi:10.1074/jbc.M111.288324 (2012). 
54 Strohman, M. J. et al. Local membrane charge regulates beta2 adrenergic receptor coupling to Gi3. Nat Commun 10, 2234, doi:10.1038/s41467-019-10108-0 (2019). 


\section{Supplementary Files}

This is a list of supplementary files associated with this preprint. Click to download.

- SupplementaryInformationNC2.pdf 